\title{
Acute and Critical Care will be indexed in PubMed, PubMed Central, Emerging Sources Citation Index, and Scopus
}

\author{
Jae Hwa Cho \\ Division of Pulmonology, Department of Internal Medicine, Gangnam Severance Hospital, Yonsei University College of Medicine, Seoul, Korea
}

On the morning of July 19, 2019, I was checking my email as usual. A message sent by "Scopus Title Evaluation Team" jumped out at me. The email was titled "The review of your title for Scopus is complete." I clicked on it, trying to calm my expectations.

The Korean Society of Critical Care Medicine first launched a journal published in Korean. As the society grew and started to hold international conferences, it decided to enhance its position and decided upon the policy of publishing a high-quality journal that would reflect well upon its reputation. As a result, the journal started to be published in English in 2014. At that time, there were numerous difficulties, as some translations into English were poor. However, with the gradual development of the journal, it finally achieved indexation in Scopus in 2019, 5 years later.

I am extremely pleased to announce this news to the readers, authors, and reviewers of Acute and Critical Care (ACC). Without their help, this achievement would not have been possible. I appreciate the selfless devotion of all past and present members of the editorial committee. I also thank all the authors who submitted their research to this growing journal. Below, I have presented a timeline of the key events in the history of the journal, leading up to its current indexation in Scopus.

September 1986: The first issue was published with 19 articles. Its name was Taehan Kugup Ǔihakhoe chi (Korean, ISSN 1229-4802).

June 1996: The name of the journal was changed to Taehan Chunghwanja Uihakhoe chi (Korean). Starting in 2010, it was published quarterly instead of biannually.

February 2014: The journal changed its official title to English (Korean Journal of Critical Care Medicine, ISSN 2383-4870) from Korean. It adopted in an English-only policy. The articles were in Korean only until 2007, and in Korean and English from 2008 to 2013.

August 2016: The journal applied to PubMed Central (PMC) for the first time.

January 2017: The journal did not pass the review for inclusion in PMC. The comments were as follows: "NLM would like to see an overall improvement in the quality of science, particularly with respect to research objectives and hypotheses needing to be defined more clearly. NLM also would like to see a greater focus on more current literature in the reference sections of articles. Finally, NLM noted that there is significantly variable writing quality in the journal."

February 2018: The title was renamed Acute and Critical Care [1].

\section{Editorial}

Received: August 20, 2019

Accepted: August 21, 2019

Corresponding author

Jae Hwa Cho

Division of Pulmonology, Department of Internal Medicine, Gangnam Severance Hospital, Yonsei University College of Medicine, 211 Eonju-ro, Gangnam-gu, Seoul 06273, Korea Tel: $+82-2-2019-3317$ Fax: +82-2-3463-3883 E-mail: jhcho66@yuhs.ac

Copyright (๑) 2019 The Korean Society of Critical Care Medicine

This is an Open Access article distributed under the terms of Creative Attributions Non-Commercial License (http:// creativecommons.org/li-censes/by-nc/4.0/) which permits unrestricted noncommercial use, distribution, and reproduction in any medium, provided the original work is properly cited. 
May 2019: The journal's first application to Scopus and second application to PMC were submitted.

June 18, 2019: The title was accepted to Scopus. The reviewers' comments were as follows: "Acute and Critical Care (25866052/2586-6060) is published by The Korean Society of Critical Care Medicine. It is publishing around 60 items per annum with limited citation activity. There is a lot of work for the editors to do to raise the standards of the journal, but there are no major red flags to accession to SCOPUS at this point."

July 4, 2019: The title passed the Scientific Quality Review by the National Library of Medicine for PMC. The technical quality evaluation was processed after the delivery of PMC XML files. Within 3 months this title will appear in PMC, pending the results of the technical evaluation.

July 2019: Clarivate Analytics included ACC in the Emerging Sources Citation Index (ESCI).

After first applying to PMC and not being accepted, the editorial team and board members have continued to do our best to improve the quality of the journal. We have revised the instructions for authors, including sections on research and publication ethics, principles of transparency and best practice of scholarly publishing, the journal's open access policy, and so on. The manuscript editor and English editors have improved the writing quality. We have collaborated with the Korean Association of Medical Journal Editors and the Korean Council of Science Editors.

Although ACC has been accepted by Scopus and PMC, it continues to face huge tasks in its future. I and the editorial team will strive to make the journal more readable and more citable.

\section{CONFLICT OF INTEREST}

Jae Hwa Cho has been the editor-in-chief of Acute and Critical Care since 2016 and an editorial board member since 2008.

\section{ORCID}

Jae Hwa Cho https://orcid.org/0000-0002-3432-3997

\section{REFERENCE}

1. Lim CM. New name of the journal. Acute Crit Care 2018;33:42. 